\title{
John Dewey e o pensamento educacional brasileiro: a centralidade da noção de movimento*
}

\author{
Marcus Vinicius da Cunha \\ Universidade Estadual Paulista - campus de Araraquara
}

\section{Introdução}

É freqüente encontrarmos, na obra do filósofo estadunidense John Dewey, referência a noções como movimento, transformação e mudança, seja para caracterizar a sociedade, o indivíduo ou a escola. A idéia de que tudo está em mutação constante, de que nada é fixo e inalterável, sem dúvida remonta aos primórdios da filosofia e é, de certo modo, banal nos dias de hoje. Quando nos deparamos com o avanço da tecnologia e com o discurso que repercute a instabilidade no mundo do trabalho, por exemplo, podemos imaginar que a concepção de que tudo se altera tenha sido aceita desde sempre. É fácil observar esse raciocínio sendo feito por pessoas que não freqüentam ambientes acadêmicos, mas não é raro encontrá-lo em nossos alunos, também naqueles que se preparam para o magistério.

Em que pesem os argumentos favoráveis à obvie-

* O presente artigo, decorrente de pesquisa financiada pelo CNPq, é a versão reformulada do trabalho "O mundo em movi-

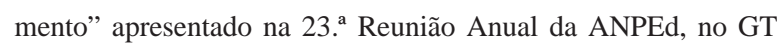
História da Educação. dade do tema, a noção de mudança ocupa posição central no pensamento de John Dewey, tendo influenciado a mentalidade dos educadores que compreenderam seu modo de pensar - o que não quer dizer, é claro, que Dewey tenha sido o único a refletir sobre a questão. A centralidade dessa idéia revela a inexistência de consenso sobre $o$ assunto, tanto no campo da filosofia quanto no da educação, seja nos Estados Unidos à época de Dewey, seja nos países em que a temática foi motivo de discussão. Não por acaso, William Heard Kilpatrick escreveu, à luz do pragmatismo deweyano, o livro $E d u$ cação para uma civilização em mudança. E não é desprezível o fato de esse mesmo livro ter sido tão bem aceito no Brasil durante décadas. ${ }^{1}$

Os marcos cronológicos do presente trabalho vão do final do século XIX a meados do século XX, época em que as sociedades ocidentais - e a sociedade norteamericana, em particular - vivenciavam profundas

${ }^{1}$ Segundo Monarcha (1997), de 1933 a 1978 o livro mencionado (Kilpatrick, 1975) foi editado nada menos que dezesseis vezes, superando a marca de 74.000 exemplares e liderando o ranking dos mais difundidos entre 1927 e 1979. 
transformações em curto espaço de tempo. A mudança assumia aspecto de celeridade jamais vista até então, seja no terreno científico, seja na economia, seja no campo da moral e dos costumes. A não ser pelas perspectivas abertas com a Revolução Russa, o capitalismo avançava sem obstáculos aparentes, expondo a face cruel de sua fase monopolista, a qual lançava empresários à falência e grandes massas de trabalhadores ao pauperismo. Nos anos de 1930, a política do New Deal surgia como tentativa de reorganização da vida econômica dos Estados Unidos, trazendo financiamento às empresas e programas sociais de combate à miséria e ao desemprego. Foi nesse ambiente que John Dewey escreveu e publicou suas obras, posicionando-se sempre em favor de uma nova ordenação social, a sociedade democrática, e de uma escola sintonizada com o movimento incessante do mundo. ${ }^{2}$

Nos anos de 1930 , os brasileiros viam o país começando a integrar-se ao processo de industrialização e urbanização que já se desenhara nas chamadas nações desenvolvidas. O ideário da modernização tomava conta dos meios intelectuais, indicando a necessidade de urgência nas transformações que deviam abranger os setores produtivos tanto quanto a mentalidade da população. A idéia modernizadora tornava imprescindível e inadiável uma total renovação de hábitos, comportamentos e modos de pensar do homem brasileiro, meta que se traduzia pelo esforço de reforma dos mecanismos de formação das elites e, principalmente, pelo intento de disciplinar o povo (Carvalho, 1998). Nesse contexto, a escola era vista como espaço privilegiado para a inserção do ímpeto transformador; uma escola transformada, evidentemente, uma educação nova, como se pôde ver no Manifesto dos Pioneiros de 1932.

Apesar da sensível distância entre o ambiente de John Dewey e a situação brasileira, o fato é que o Brasil viveu, nas décadas de 1930 a 1950, momentos claramente marcados pelo espírito de modernização, sinônimo de mudança urgente, única via capaz de colocar

${ }^{2}$ Desenvolvo esse tema no livro John Dewey: a utopia democrática (Cunha, 2001b). o país em pé de igualdade com as nações mais prósperas do mundo ocidental. Esse movimento culminou, nos marcos aqui estabelecidos, com o predomínio do ideário desenvolvimentista abraçado pelo governo Kubitschek, quando a educação veio a assumir, mais uma vez, o papel de agência de socialização das novas gerações, mediante a incorporação das técnicas e dos resultados oriundos da pesquisa científica (Cunha, 1991).

O objetivo do presente artigo é mostrar que a concepção deweyana de movimento - entendida como sinônimo de mundo em mudança - desempenhou papel sobremaneira relevante no pensamento educacional renovador brasileiro naquelas décadas. Se hoje ainda desempenha, talvez não seja com a mesma conotação de antes, o que poderemos analisar no final deste trabalho. Para iniciar, faremos uma breve explanação sobre como o tema se apresenta em Dewey, relacionado a outros que compõem o pensamento deweyano, no intuito de contemplar subsídios para que o leitor situe o conteúdo das seções seguintes e compreenda as discussões feitas pelos brasileiros sob a inspiração de John Dewey.

Em seguida será feita a apresentação de escritos publicados no Brasil no período entre 1930 e 1960, cada qual circunscrito a determinadas temáticas específicas. Cabem aqui certos esclarecimentos de natureza metodológica. A pesquisa que deu origem a este trabalho foi baseada na análise de publicações periódicas distribuídas ao longo de três décadas, ${ }^{3}$ sendo que neste momento será privilegiada a exposição das idéias de alguns dos educadores pesquisados, tendo em vista apenas os critérios de representatividade e clareza de suas opiniões, o que limita o escopo de pretensões deste estudo e torna impossível adentrar na complexidade do pensamento dos autores, muito menos dos determi-

${ }^{3}$ São elas: Escola Nova, Educação e Revista de Educação, série do governo paulista, pesquisada entre 1930 e 1945; Revista Brasileira de Estudos Pedagógicos do INEP, entre 1944 e 1960; Educação e Ciências Sociais do Centro Brasileiro de Pesquisas Educacionais, de 1956 a 1960, e Pesquisa e Planejamento do Centro Regional de Pesquisas Educacionais de São Paulo, de 1957 a 1960 . 
nantes da época em que escreveram. A intenção, bem mais modesta, é mostrar que, nos vários assuntos abordados, a noção de movimento desempenha o papel de eixo em torno do qual circulam as idéias educacionais. Trata-se de uma abordagem que busca atingir um único fim: posicionar a tese de que a noção de mundo em movimento era essencial para os autores brasileiros, como era para Dewey. Com isso, esperamos fornecer matéria-prima para futuras investigações, mais aprofundadas e contextualizadas.

Em verdade, esse modo de proceder, em que se opta pelo recorte das manifestações dos autores, pode soar como injusto diante das inúmeras e variadas contribuições que os mesmos ofereceram ao desenvolvimento da educação brasileira. No entanto, essa aparente injustiça só pode ser minimizada pela multiplicação de estudos monográficos que se dediquem a vasculhar arquivos em busca de fontes primárias, pelas quais torna-se possível conferir precisão e amplitude às idéias de cada um dos educadores que construíram o movimento de renovação das idéias e práticas pedagógicas no Brasil.

\section{Movimento, educação e democracia}

O tema da transformação das coisas aparece em Dewey especialmente na obra Reconstrução em filosofia, originalmente publicada em 1920, fortemente associado a ciência, filosofia e verdade. Nesse livro, o autor considera que

\footnotetext{
o mundo em que até os homens mais inteligentes dos tempos idos julgavam viver, era um mundo fixo, um domínio onde qualquer mudança somente se processava dentro de limites imutáveis de inação e permanência, um mundo onde a fixidez e a imobilidade... era superior, mais importante em qualidade e autoridade, do que o movimento e a mudança. (Dewey, 1959b, p. 82)
}

Tratava-se de um universo ideal composto por "reduzido número de classes, espécies, formas, distintas e separadas em qualidade", organizadas hierarquicamente "numa ordem graduada de superioridade e inferioridade", um mundo fechado por fronteiras mui- to bem definidas e fixas, em que a vivência dos homens não tinha relevância.

Os pensadores que refletiram sobre tal idealização não conseguiram romper com a idéia de imutabilidade, razão pela qual, de Platão a Hegel, praticamente todos os filósofos expressaram a primazia de valores transcendentais para desqualificar a experiência humana, tão suscetível à mudança. Onde quer que houvesse mudança, haveria instabilidade, deficiência e imperfeição: "Daí, ter de ser a completa e verdadeira Realidade imutável, inalterável, tão repleta de Ser que sempre e para sempre se mantém em fixo sossego e repouso" (idem, p. 119).

Para Dewey, a filosofia não deve ser vista como um conhecimento sobre essa Realidade, como se fosse "o último e mais elevado termo da contemplação pura" (idem, p. 121). A proposta deweyana é que a filosofia seja uma reflexão sobre a experiência dos homens no mundo real e não uma guardiã da Verdade, um farol condutor da humanidade na direção do Bem. Ao substantivo "verdade" e ao adjetivo "verdadeiro", Dewey prefere o advérbio "verdadeiramente", indicando assim recusar a filosofia como guia do homem, mas aceitando-a, por outra via, como norteadora de uma forma de agir, de um modo de proceder em busca de algo uma busca contínua, dada a mutabilidade incessante do mundo (idem, p. 154).

Para que seja desse modo, é imprescindível que a mudança deixe de ser vista como pecado ou descuido da natureza, reflexo da imperfeição do Ser. Essa perspectiva é comparada por Dewey à atitude científica, da qual historicamente resulta: "o método experimental empenha-se em quebrar toda e qualquer fixidez aparente e em provocar mudanças" (idem, p. 123), buscando sempre um conhecimento prático, não contemplativo, um saber oriundo da experiência e destinado à solução dos assuntos humanos. É assim porque, para a ciência, o que existe é

\footnotetext{
um universo ilimitado no espaço e no tempo, sem limites aqui ou ali, nesta extremidade, por assim dizer, ou naquela, e tão infinitamente complexo na estrutura quanto na extensão. Daí, ser também o universo um mundo aberto, infinitamente variegado, mundo que, no velho sentido, a custo pode
} 
ser chamado de universo; tão múltiplo e extenso que não há possibilidade de o sintetizar e condensar em nenhuma fórmula. (Dewey, 1959b, p. 86)

Conforme podemos observar, mudança é um tema a que Dewey recorre para caracterizar o universo aberto, variado e instável que propicia as práticas científicas, as quais, por sua vez, inspiram a nova atitude filosófica que propõe. Outros temas associam-se naturalmente a estes, como a pesquisa científica, a ordem social e a educação.

Do posicionamento que considera as teorias simplesmente como hipóteses até que sejam comprovadas experimentalmente, Dewey extrai a noção de que a pesquisa científica não deve considerar a existência de qualquer "fim particular de antemão estatuído" (idem, p. 147). Mas vai além, afirmando que a investigação científica só faz sentido quando os pesquisadores rompem os limites de suas especializações e "entram em franca cooperação com outras ocupações sociais, e se mostram sensíveis aos problemas de seus semelhantes, ao ponto de lhes transmitirem os resultados, a que porventura hajam chegado, para mais ampla aplicação no domínio da ação" (idem, p. 148).

Tanto a filosofia quanto as atividades científicas, portanto, devem servir a um projeto de sociedade, o que só é possível com o abandono de verdades imutáveis e de práticas de investigação socialmente descomprometidas. A sociedade almejada por Dewey é a democracia, um modo de vida cooperativo em que todas as definições advém de consensos obtidos mediante livre e aberta participação de todos. A democracia pode ser alcançada somente por intermédio da reconstrução moral se os conhecimentos e métodos da ciência puderem contribuir para tanto, o que exige o rompimento da "separação que se faz entre ciência natural de um lado e ciência moral de outro".

Quando a física, a química, a biologia, a medicina, contribuem para a descoberta dos sofrimentos humanos, reais e concretos, bem como para aperfeiçoar os planos destinados a remediá-los e a melhorar a condição humana, tais ciências se fazem morais: passam a constituir parte integrante do aparelhamento da pesquisa ou ciência moral. Esta perde então seu peculiar sabor didático e pedante, seu tom ultramoralístico e exortativo. (Dewey, 1959b, p. 166)

A educação escolar integra-se a esse projeto de reconstrução por várias razões, como se pode ver no livro Democracia e educação, em que Dewey atribui aos educadores a responsabilidade de utilizar a ciência para modificar atitudes e hábitos de pensamento pouco adequados ao projeto de construção da sociedade democrática. A educação é campo fértil para a filosofia por fornecer o espaço de investigação que esta necessita para testar suas hipóteses sobre o homem, mais precisamente sobre o homem em coletividade. Vem daí a concepção deweyana de que a filosofia pode ser vista como a "teoria geral da educação", se esta for entendida como "processo de formar atitudes fundamentais, de natureza intelectual e sentimental, perante a natureza e os outros homens".

Em nenhum outro locus encontra-se espectro tão amplo de mudança e transformação como no processo educacional, em que o indivíduo deixa o estado infantil para tornar-se adulto. Portanto, é ali que a filosofia deve atuar, desde que não se limite a "permanecer simbólica - ou verbal - ou um deleite sentimental para poucos, ou então como meros dogmas arbitrários" (Dewey, 1959a, p. 362). Assim, a filosofia na educação, no campo próprio do movimento, mediante a inspiração fornecida pelo método científico, pode desenvolver atitudes capazes de contribuir para a edificação da sociedade democrática.

\section{Filosofia, ciência e democracia ${ }^{4}$}

O primeiro e mais destacado autor a mencionar John Dewey nos periódicos brasileiros analisados foi Anísio Teixeira. Em artigo que abordava o movimento de renovação educacional que vinha ocorrendo nos Estados Unidos da América, seu objetivo era mostrar que aquele movimento encontrava-se fortemente centrado na remodelação dos programas escolares, que

${ }^{4}$ Esta seção e a seguinte trazem trechos adaptados de dois outros artigos (Cunha, 1999a; 1999b), em que os mesmos temas são discutidos com outros objetivos. 
deveriam tornar-se "o traço de união entre a criança e a vida social americana", corolário da tese deweyana de que "os movimentos educativos devem refletir as mudanças sociais". Nesse escrito, a presença de procedimentos científicos no campo educacional era claramente formulada, pois Teixeira entendia que, sob a influência de Dewey, os norte-americanos buscavam "fixar as diretrizes de uma teoria de educação moderna e científica", por meio de métodos e princípios prescritos pela “ciência da educação” (Teixeira, 1930, p. 87).

Tal ênfase do autor, no entanto, não significava excluir a discussão sobre valores, como se esta pudesse ser substituída por respostas vindas de teorias científicas ou de necessidades ditadas pela ordem social. Não se tratava de defender a simples adaptação dos programas de ensino - e, conseqüentemente, dos educandos - à moderna sociedade americana, o que poderia transformar a educação numa engenharia destinada à massificação dos indivíduos. Anísio Teixeira tinha em mente o conceito deweyano de democracia, que implicava, segundo ele, movimento constante. $\mathrm{O}$ ambiente social em que se davam as novas concepções pedagógicas era a vida democrática "em permanente progresso", pois a sociedade democrática era uma "sociedade em indefinido estado de reconstrução" (idem, p. 88).

Assim, a escola jamais iria tornar-se uma agência de "fornecimento de crenças, ideais e conhecimentos fixos e herdados das experiências anteriores", mas seria, sim, um instrumento de permanente "inquérito e reconstrução social", nem à mercê das ciências, nem do estado atual da sociedade, uma vez que as "transformações econômicas e industriais do mundo e as conquistas científicas" conduzem obrigatoriamente à incessante revisão da ordem social (idem, p. 89).

O que é importante ressaltar nesta breve análise é que noções como movimento, mudança e transformação constantes ocupavam lugar central no pensamento de Anísio Teixeira, traduzindo a idéia de que a escola, a sociedade e o progresso científico jamais assumem formas estáticas e definidas, quando em ambiente democrático. A "sociedade em permanente mudança”, sob a democracia, continha, em sua essência, a possibilidade de conflito, discussão e reflexão dirigidas pela coletividade. No contexto de uma sociedade assim, em "indefinido estado de reconstrução", os problemas educacionais não podiam ser vistos como estritamente técnicos, solucionáveis pela mera aplicação de saberes científicos, supostamente objetivos e inquestionáveis. As questões educacionais apresentavam-se, então, como "um problema de filosofia de educação" (idem, p. 90).

Em outro escrito, Anísio Teixeira reafirmava essa mesma concepção inspirada em Dewey, dizendo que "a democracia não é um fato histórico pretérito, que estejamos a procurar repetir, nem uma previsão rigorosamente científica a que possamos chegar com fatal exatidão determinística”. Deste modo, a democracia, "uma afirmação política, uma aspiração, um ideal ou, talvez, uma profecia", não se apresentava como algo que pudesse ser alcançado por intermédio da ciência, mas sim por meio da capacidade humana para atingir uma "vida associada, que todos partilhem igualmente" (Teixeira, 1956, p. 15).

Segundo o autor, os resultados do trabalho científico não produziriam, automaticamente, uma escola melhor e, assim, uma sociedade melhor. Embora a educação devesse submeter-se ao crivo das ciências, tornando seus procedimentos intencionais e guiados por metas bem definidas, suas finalidades seriam estabelecidas no âmbito dos valores desenvolvidos no ambiente democrático. As ciências ajudariam na construção de processos escolares mais igualitários, é verdade, mas não poderiam ser responsabilizadas diretamente pela vida democrática - uma aspiração, um ideal, uma profecia, segundo o próprio Anísio Teixeira. ${ }^{5}$

Teixeira mostrava também, em outro texto, que a transformação da escola seria feita mediante estreito intercâmbio da ciência com a filosofia. Apoiada nos conhecimentos científicos existentes, a filosofia deveria tornar-se uma disciplina voltada para a compreen-

${ }^{5} \mathrm{~A}$ análise da filosofia deweyana na educação escolar encontra-se também em Teixeira (1959). O conceito de democracia em Dewey também foi analisado por Jayme Abreu (1960). 
são e a regulação da conduta humana. Os fins superiores ou espirituais, como a liberdade humana, a realização da fraternidade e a efetivação da felicidade pessoal e coletiva, eram postos como dependentes das crenças que os seres humanos desenvolvem ao longo de sua história, podendo ser investigados objetivamente pela ciência, que por sua vez fornece subsídios para a filosofia (Teixeira, 1955b, p. 16).

Sob esta visão deweyana, em que são rompidas as dicotomias entre ciência e filosofia, em que o mundo está em constante movimento sob o impulso do modo de vida democrático, o conhecimento científico era apresentado, sempre, como provisório. Em última instância, isto significava dizer que os produtos do trabalho científico, seja no âmbito restrito de sua elaboração, seja no campo mais amplo em que são apropriados pela sociedade, submetem-se, invariavelmente, à experiência humana, que é, por sua vez, essencialmente social. Tanto o empenho dos cientistas para dominar os fenômenos naturais, individuais e sociais, quanto a transposição dos saberes daí resultantes para terrenos alheios ao de sua elaboração, subjugam-se a definições que dependem da coletividade, esta também em permanente movimento.

\section{Verdade e contingência}

A formulação original e o desenvolvimento das teorias científicas têm sua razão de ser no campo da filosofia, entendida esta disciplina como aquela que propicia discussão permanente sobre a vida humana e não como conjunto de dogmas definidores da verdade eterna e imutável. Esta concepção, cujo fundamento advém da teoria lógica de Dewey, era explicada por Anísio Teixeira em outro ensaio, no qual a principal e decisiva diferença entre a filosofia deweyana e as demais escolas filosóficas era localizada na percepção da "contingência e precariedade do mundo", o que inscrevia o "sentido da vida humana no próprio risco e aventura do tempo e da mudança".

Por esse ângulo, em que novamente sobressai a noção de movimento e mudança permanentes, Dewey era mostrado não como um formulador de verdades, mas como um elaborador de "interpretações, valorizações e orientações", para guiar "a aventura da civilização e da própria vida". Parafraseando Dewey, Anísio Teixeira dizia que a "confusão filosófica" instalada em sua época era decorrente de os filósofos insistirem na afirmação de uma realidade "superior à precariedade e contingência do universo" (Teixeira, 1955a, p. 4). ${ }^{6}$

Tais formulações resumiam a tese deweyana de que não é papel da filosofia ocupar-se com a definição de verdades superiores, transcendentais, imutáveis, permanentes. A filosofia devia ser uma contribuição para o aclaramento do sentido da vida, um esforço infindável, posto que o sentido da existência de seres social e historicamente determinados altera-se a cada momento. O papel do filósofo devia ser guiado não pela busca da Verdade, mas pelo reconhecimento da mutabilidade permanente do mundo, acompanhado pelo olhar crítico dirigido às necessidades sugeridas pela experiência coletiva.

No artigo em que comentava o movimento de renovação educacional dos Estados Unidos, acima mencionado, Anísio Teixeira aplicava esse mesmo raciocínio à educação, apontando aquilo que lhe parecia mais vulnerável naquele país: a ênfase colocada no "aspecto objetivo da educação", uma tendência para captar, por meios estatísticos, o perfil dos programas escolares, das profissões, das habilidades necessárias à aprendizagem, enfim, dos fatos e conceitos vigentes no sistema educacional e úteis à sua eficiência. Tais investigações científicas serviam, segundo ele, para mostrar a situação educacional lá existente como se fosse um ideal a ser seguido e praticado.

Em outras palavras, os recursos mensuracionistas da ciência, ao revelarem o aspecto imediato de alguma coisa, acabavam por contribuir para que esta mesma coisa fosse vista como verdade permanente e imutável. Este quadro induzia a considerar que a escola devia submeter-se àquilo que vigorava num dado momento na sociedade. Enfim, uma escola guiada por

${ }^{6}$ A este mesmo assunto também foi dedicado um artigo de Newton Sucupira (1960). 
princípios imediatistas e utilitaristas, como se o mundo circundante fosse estático, imóvel.

Apoiado em idéias deweyanas, Anísio Teixeira mostrava que os recursos científicos, capazes de revelar o existente, eram impotentes para elucidar a verdade. Embora fosse possível captar objetivamente o estado da sociedade e da escola num certo momento e, mediante esses dados, concluir quanto à eficiência de determinados procedimentos, esta não devia ser a abordagem adotada para definir o caminho a ser seguido pelos educadores. "Contra essa visão mecânica", dizia Teixeira, "devemos acentuar que, se a ciência pode determinar as matérias de educação, a finalidade e os objetivos dela serão sempre objeto de uma larga orientação filosófica e social" (Teixeira, 1930, p. 95).

No universo deweyano de Teixeira, orientação filosófica significava permanente discussão no campo dos valores. Orientação social, por sua vez, pressupunha a vigência de um ambiente democrático, segundo os parâmetros já delineados acima. O estudo objetivo da sociedade e da escola seria útil como instrumento adicional para fornecer elementos com os quais a sociedade poderia discutir o seu destino e o destino de sua escola. Esta última tarefa seria obra do pensamento, da reflexão e da crítica, enfim, da filosofia - auxiliada, por certo, mas apenas auxiliada, pelos recursos da ciência.

Outro autor que também comentou o movimento pedagógico norte-americano foi Lourenço Filho que, em artigo da mesma época, apresentou uma classificação da pedagogia naquele país e situou, nela, John Dewey. De acordo com Lourenço Filho, lá havia um grupo que enfatizava os valores tradicionais e entendia que as técnicas educativas deviam "submeter-se a uma filosofia rigidamente definida"; outro grupo insistia no valor das técnicas de ensino, por si mesmas; e um terceiro não admitia os progressos da técnica senão "para os fins de alteração nos próprios objetivos da educação", objetivos estes considerados variáveis "no tempo e no meio, segundo as alterações da vida social" decorrentes da experiência (Lourenço Filho, 1939, p. 17). Era nessa última categoria que Lourenço Filho situava John Dewey.
Como se pode notar, tal caracterização de Dewey continha as noções de variabilidade e mutabilidade das metas educacionais, idéias muito próximas daquelas que já vimos acima expressas por Anísio Teixeira: a definição do pensamento deweyano por meio das noções de movimento, mudança e transformação constantes. Por isso mesmo, Lourenço Filho também compreendia que, para Dewey, a verdade não possuía “senão um caráter 'instrumental', para servir à atividade humana", e que a democracia era o estado social ideal, em que a cooperação é exercida plenamente e oferece iguais oportunidades de desenvolvimento a todos (idem, p. 18).

Ao que parece, essa concepção de verdade, como algo contingente ao movimento da sociedade, desagradava profundamente os pensadores católicos. Em escrito publicado logo no início do período aqui analisado, Tristão de Athayde (1932, p. 77) afirmava ser impossível aceitar a concepção moral de Dewey por ela não contemplar "princípios objetivos e ideais fixos que derivem de uma concepção total da vida". Athayde percebia não haver, em Dewey, a proposição de uma ciência normativa das ações humanas, pois o pensador norte-americano rejeitava "toda consideração do sobrenatural, do transcendente, do universal e do fixo na vida".

Assim, as noções deweyanas de mudança, transitoriedade e alteração incessantes da ordem social implicavam a aceitação de verdades também transitórias, o que conduzia, segundo o ideólogo católico, uma ética desprovida de fundamento, pois baseada no desdém pelos "princípios fundamentais das coisas". Observe o leitor que, em oposição à idéia de movimento do mundo, da sociedade e da escola, idéia sempre presente na concepção deweyana de Anísio Teixeira, o pensador católico apresentava expressões que remetiam à fixidez das coisas, ao estabelecido, àquilo cuja natureza e essência jazem imutáveis e que podem ter seus fundamentos definidos uma vez e para sempre.

${ }^{7}$ Essa observação abre interessante perspectiva para pesquisar a visão dos católicos a respeito de Dewey - o que vimos fazendo em projeto de Iniciação Científica financiado pela FAPESP. 


\section{Pesquisa educacional}

A investigação científica no campo educacional foi tratada por João Roberto Moreira mediante a problematização de alguns dos temas já destacados acima, como a integração entre filosofia e ciência, característica do pensamento deweyano, e a preocupação com os aspectos objetivos - ou fixos - da educação como norteamento de pesquisa. Em um de seus artigos, o autor analisava o papel das ciências sociais como instrumento para melhor conhecimento do homem e da sociedade, tema que discutia no âmbito de duas grandes linhas de orientação, a européia e a norte-americana.

Na primeira linha, influenciada por Durkheim, a educação seria "uma resultante, mais que uma condicionante das mudanças sociais" (Moreira, 1956, p. 48), o que implicava, segundo a tradição "ideo-positivista", compreender a escola por intermédio de estudos sociológicos limitados "aos problemas da realidade existente". Por esta via, a pesquisa deveria contentar-se em compreender e explicar fatos, sem adentrar em questionamentos de natureza valorativa dos mesmos. Os "problemas práticos", cuja solução exige discutir valores morais, inatingíveis pela razão positiva, são deixados para o campo de uma "filosofia axiológica" (idem, p. 49).

$\mathrm{Na}$ apreciação feita por J. R. Moreira, pode-se perceber que a vertente durkheimiana era tida como competente para apreender a realidade do mundo e da educação em seus aspectos fixos, momentâneos, imóveis. Daí ser impossível discutir, em seu interior, os aspectos valorativos implicados na vida prática, posto que estes só se revelam na perspectiva da mudança, da transformação, do movimento. Pela matriz deweyana, segundo o autor, o que interessava era justamente ultrapassar o nível meramente descritivo dos fenômenos e abordar situações que envolvessem os tais "problemas práticos", repletos de interrogações quanto à "intenção normativa ou construtora" dos envolvidos.

O espírito norte-americano, muito afeito "à mudança, ao aperfeiçoamento e ao progresso, quer social e político, quer econômico e tecnológico", tinha a es- cola como campo de análise científica de fatos, sim, mas também como campo passível de considerações no tocante a finalidades e valores. Era assim porque a perspectiva integradora de John Dewey havia trazido, para o interior da investigação científica, tanto a realidade existente quanto os problemas normativos, colocando todo esse conjunto sob a tutela de um mesmo empenho investigativo - por ele denominado científico (idem, p. 49).

João Roberto Moreira privilegiava o estudo da educação por intermédio das ciências sociais, desde que as investigações assim conduzidas fossem vistas sob o enfoque deweyano, contrário à dicotomia entre ciência, de um lado, e filosofia, de outro. $\mathrm{O}$ apelo às ciências sociais seria norteado, em última instância, pela tentativa de compreender "o homem no mundo contemporâneo", sendo assim útil à busca de um "conceito do homem" na educação (idem, p. 55). No campo das ciências sociais aplicadas à compreensão dos fenômenos educacionais, era preciso estar atento para não adotar atitudes dicotomizadoras que colocassem os recursos mensuracionistas, descritivos e explicativos contra a discussão dos fins implicados no objeto investigado. Na perspectiva de Moreira, ficaria evitado o risco de tornar a pesquisa socioeducacional um mero exercício de coleta de dados, desligado da efetiva discussão dos compromissos políticos, sociais e morais nela envolvidos.

Se nesse caso o autor parecia concordar com Anísio Teixeira quanto à aceitação das idéias deweyanas, fazendo eco ao já mencionado equívoco de nortear a pesquisa para o "aspecto objetivo da educação", em outro escrito - publicado, aliás, anteriormente ao que acaba de ser mencionado - Moreira manifestava preocupação quanto ao emprego da via pragmatista, tendente a tornar-se, segundo ele, um perigoso "utilitarismo solipsista" (Moreira, 1954, p. 35). Ao permitir questionamento constante quanto à exatidão e universalidade das leis científicas, o pragmatismo poderia conduzir à indistinção entre o verdadeiro e o falso, bem como à ausência de critérios para decidir sobre o aproveitamento dos produtos da ciência. Por este caminho, o perigo estaria em transformar as balizas do eu soli- 
tário em parâmetro único para a tomada de decisões, o que faria o julgamento moral sobre a validade das coisas levar em conta tão-somente a utilidade imediata do conhecimento científico, na esfera de necessidades particulares, individuais e isoladas, por vezes mesquinhas, de pessoas, grupos ou nações.

Tais críticas, que afirmavam o potencial da ciência para revelar verdades, destinavam-se a apontar uma estreita ligação entre o pragmatismo deweyano e a sociedade capitalista de sua época - ao que parece, o grande alvo do pensamento de J. R. Moreira. Negando-se a investigar a essência das coisas e buscando discutir sua validade na "vida prática", o pragmatismo revelava-se como um resultado inegável da era industrial, "por isso mesmo, unilateral e nitidamente capitalista" (idem, p. 36). Em extensa nota inserida em outro ensaio de sua autoria (Moreira, 1957), o autor apresentava as teses de Dewey como aplicáveis apenas à nascente sociedade norte-americana do início do século, um mito por ele idealizado.

Visto por este ângulo, o que Moreira estaria dizendo é que as concepções deweyanas tomavam o mundo existente - ou o mundo que existia apenas em fantasia - como representativo da verdade. Ao renegar a busca descomprometida da Verdade essencial e imutável, Dewey deixava-se seduzir por uma única verdade, verdade momentânea e unilateral, o mundo capitalista como verdade. Assim, impressionado pela vida prática atual, Dewey teria tomado esta mesma vida em sua fixidez, deixando escapar o movimento, a possibilidade de mudança, um mundo alternativo a ser construído pela coletividade. Deste modo, Dewey seria a negação das próprias teses deweyanas.

Jayme Abreu (1959, p. 49) entendia de outro modo o posicionamento político de Dewey, para ele um crítico da "vida atual" americana por fazer severas restrições à "sociedade capitalista, baseada no princípio aquisitivo como meta suprema e medida final do sucesso". Nada mais avesso às concepções deweyanas do que a perspectiva de tomar a realidade imediata como parâmetro de sociedade ideal, tanto quanto a pretensão de "planejamento total da sociedade" em que "crenças medievais, ortodoxas" fossem incorporadas como "fins fixos e definitivos". Para Abreu, tanto o passado imóvel quanto o presente fossilizado eram rejeitados pelo pragmatismo deweyano.

O certo é que Moreira não concordava integralmente com as noções do pragmatismo, nem apoiava a totalidade das idéias de John Dewey, como chegou a afirmar em outro trabalho (Moreira, 1957, p. 74-75), e tinha divergências quanto às posições de Anísio Teixeira. Não concordava com a afirmação do caráter temporário dos conhecimentos resultantes da ciência, para ele capazes de estabelecer formulações gerais universalmente válidas, o que era necessário para distinguir a ciência do senso comum. ${ }^{8}$ Temia que, sob essa orientação, as investigações científicas pudessem incorrer em equívocos utilitaristas e subjetivistas, tornando-se práticas irrefletidas a serviço de interesses localizados e imediatos - a sociedade capitalista, como já vimos. Dada a necessidade de posicionar o papel das ciências, particularmente das ciências sociais, como instrumento útil à compreensão do universo social e educacional brasileiro, J. R. Moreira via-se impossibilitado de concordar com o relativismo que via insinuar-se perigosamente nas formulações deweyanas.

Embora fosse assim, o autor defrontava-se com uma situação que o levava a mudar seu posicionamento contrário às concepções pragmatistas. Segundo ele, os resultados da investigação científica ainda eram por demais fragmentados, incapazes de dar conta dos desafios colocados pela realidade social. Em meio a esse "pluralismo de teorias e leis... muitas vezes paralelas e divergentes, por lhes faltar unidade", não podia haver outro critério de escolha "senão o da utilidade prática”, concluía. Daí concordar, por fim, com o pragmatismo, visto como "uma resultante da tomada de consciência da evolução histórica das ciências" (Moreira, 1954, p. 36).

Para Moreira, já não se tratava de proceder a uma análise dos aspectos morais da filosofia deweyana, mas a um julgamento quanto ao valor das pesquisas científicas vistas sob o enfoque desta mesma filosofia. As

${ }^{8}$ Em uma nota no artigo de Teixeira (1955a, p. 21), Moreira mostra a diferença que vê entre ciência e senso comum. 
teorias deviam ser vistas, então, como "instrumentos de trabalho", e os resultados científicos ganhariam valor como "um meio, em constante aperfeiçoamento, para afirmar nosso domínio sobre o mundo real e modificálo para nossa utilidade", dizia o autor (idem, p. 37).

Enfim, a insuficiência momentânea das conclusões científicas - "paralelas e divergentes", sem unidade - impunha que J. R. Moreira considerasse a adoção de critérios externos a este campo para julgar seus resultados. No caso específico da educação, quando a escola encontra-se cercada por problemas sociais gravíssimos, faz-se necessário adotar uma "regra de ação científica: a da pesquisa imediatamente comprometida com problemas práticos, específicos e imediatos". Torna-se desprovido de sentido, em tais momentos, "qualquer atitude purista em ciência da educação" que venha postergar a reforma inadiável das instituições educacionais e das práticas pedagógicas.

Infelizmente Moreira não esclarecia, com a devida precisão, o quadro fragmentário que representava, para ele, a ciência de sua época. O que se pode compreender é que o estado de desenvolvimento das leis e teorias científicas era insuficiente para dar conta dos problemas a serem concretamente solucionados - talvez pelo fato de o mundo ser um lugar em constante e acelerada mudança e não um lugar estacionário, passível de ser explicado pela ciência, ao menos por uma ciência que se propusesse a compreender o estado atual da sociedade, a exemplo da vertente durkheimiana, conforme descrita pelo próprio Moreira. Se for assim, Moreira rendia-se ao pragmatismo pelas mesmas razões que Dewey.

Pelo raciocínio de Moreira, se não é válido distanciar as ferramentas de investigação científica da definição de valores, e se estes não devem ser ditados por preferências particulares e isoladas, também não é possível aceitar uma ciência desenvolvida e aplicada que não seja submetida "a um programa de necessidades nacionais" (idem, p. 45). Embora restasse definir o sentido da expressão "programa de necessidades nacionais", este seria o critério de definição dos fins da educação e do aproveitamento dos conhecimentos científicos no campo educacional. Eis um critério bastante condizente com os princípios pragmatistas, aliás, pois leva em consideração a incapacidade de as ciências apontarem rumos para a educação escolar. Além disso, sugere uma discussão política sobre os destinos da comunidade. Se considerarmos o enquadramento deweyano presente em Anísio Teixeira, esta seria uma discussão a ser feita em ambiente democrático tendo em vista a melhoria da vida individual e social.

\section{Ciência e arte}

A análise dos escritos publicados nos periódicos educacionais pesquisados sugere que o pensamento de John Dewey foi empregado, ao longo do período em estudo, com o intuito de mostrar a relevância dos procedimentos científicos na educação, desde que estes não fossem tomados como capazes de definir as finalidades da prática pedagógica. Ao lado da ciência, colocava-se a necessidade de reflexão sobre os fins educacionais a ser feita no terreno da filosofia, mas não de uma filosofia comprometida com determinações metafísicas quanto ao sentido do homem e da sociedade. A percepção de um mundo em permanente mudança foi determinante para impedir que a tomada de dados relativos ao estado atual da sociedade e da escola por intermédio das ciências - fosse o critério norteador da educação. Essa mesma percepção foi decisiva para impedir, no campo da filosofia, que os educadores guiassem seus propósitos pela crença na imutabilidade da natureza humana.

Mas se a mutabilidade do mundo impedia que a educação fosse vista como uma ciência, embora permeada pelos conhecimentos dali oriundos, seria ela então uma arte? Ao ressaltar aspectos como a vida atual e as necessidades do momento, e ao renegar "qualquer atitude purista em ciência da educação", como dizia J. R. Moreira, não estaria o discurso deweyano deixando os procedimentos pedagógicos à mercê da vontade, da subjetividade, da criatividade e de outros atributos individuais dos educadores e dos educandos? ${ }^{9} \mathrm{E}$

${ }^{9}$ Discuto essa concepção pedagógica frente às formulação deweyanas no artigo Dewey, escola nova e construtivismo (Cunha, 2001a). 
como seria a pesquisa educacional conduzida sob essa perspectiva, em que a realidade - e a realidade escolar, em especial - é constantemente alterada?

Jayme Abreu procurava esclarecer estas questões em um escrito que distinguia três grandes grupos de filosofias educacionais e suas respectivas implicações no campo da pesquisa: o autoritarismo ou dogmatismo educacional, que via a educação como determinada por influências exteriores ao indivíduo; o laissez-faire ou romantismo educacional, que concebia a educação como resultado de fatores inerentes ao indivíduo; e o experimentalismo educacional, em que se encontravam John Dewey e outros pensadores norte-americanos, cuja teoria advogava ser a experiência educativa resultado da interação entre indivíduo e ambiente. ${ }^{10}$

Com base nessa última corrente de pensamento, o autor analisava as demais, fazendo críticas ao autoritarismo educacional por colocar as investigações científicas como determinantes das práticas pedagógicas. Assim, dizia o autor, essa filosofia contém um enfoque que atribui ao cientista educacional poderes para selecionar "os melhores métodos de ensino para cada matéria," bem como definir os objetivos educacionais (Abreu, 1958, p. 81). O problema estava justamente na colocação da ciência como determinante da educação, inclusive de seus fins, perspectiva que sugere a existência de uma ciência da educação, produzida externamente ao campo educacional, como "um corpo autônomo de matéria comparável ao de ciências bem estruturadas", algo que Abreu refutava veementemente (idem, p. 84).

Nesse mesmo grupo, o dogmatismo educacional, Abreu via uma outra tendência que, ao partilhar da idéia de que a educação não constitui um "corpo de matéria científica, correspondente ao de ciências autônomas," (idem, p. 85-86) acaba sustentando ser a educação uma arte. Por essa via, todos aqueles que se empenham em pesquisar para descobrir novos métodos e objetivos educacionais estariam prejudicando o bom andamento da escola, uma vez que o ensino é vis-

${ }^{10}$ Abreu baseava-se no livro Philosophies of education, from the standpoint of the philosophy of experimentalism, de J. P. Wyne. to como fundamentado apenas na vocação do bom professor, no domínio dos conteúdos a ensinar e no senso comum. "O professor deve ser um artista - diziam os adeptos dessa posição, segundo Abreu - e qualquer esforço para fazê-lo um cientista será não apenas fútil, mas hostil mesmo ao magistério" (idem, p. 87).

A crítica do autor, nesse caso, incidia no total desprezo dos dogmáticos pelos conhecimentos científicos, importantes, segundo ele, para formar o "professorartista". A expressão professor-artista significava, para Abreu, que a educação, se não era de fato uma ciência, não deixava de ser uma arte. Era uma arte que, mediante os conhecimentos revelados pela ciência, tornava-se cada vez mais científica. $\mathrm{O}$ posicionamento de Abreu visava, deste modo, lançar por terra "a antítese entre as concepções de educação como arte e como ciência" (idem, p. 88). A pesquisa científica, assim, era vista como fundamental para o sucesso das práticas pedagógicas, desde que não ficasse com a responsabilidade de ditar externamente os fins e os meios dessas mesmas práticas.

Nesse ponto, Abreu aceitava algumas das formulações do laissez-faire, segundo as quais a verdadeira pesquisa devia ocorrer no campo da prática escolar, integrando professores e alunos, todos envolvidos em alcançar suas metas educacionais mediante o conhecimento preciso da escola e da comunidade. A crítica do autor aos adeptos desse romantismo educacional indicava que estes se equivocavam ao ater-se a aspectos muito particularizados da situação cotidiana, o que determinava afastar o pesquisador de estudos e investigações aplicáveis a situações mais gerais. Além disso, esse tipo de abordagem tendia a tomar os objetivos imediatos dos alunos como se fossem objetivos da educação.

Conclui-se, então, que o experimentalismo educacional, a corrente deweyana apoiada por Jayme Abreu, rejeitava tanto a idéia de a educação ser uma ciência, quanto a concepção que indicava ser ela puramente uma arte. Tratava-se, isto sim, de uma arte capaz de tornar-se, pelo contato íntimo com as ciências, mais científica, sem deixar de ser arte e sem render-se a saberes produzidos em campos exteriores à 
escola. A pesquisa científica, feita no interior da própria escola, não devia tomar a realidade imediata ou os desejos momentâneos de professores e alunos como ideais a serem seguidos, pois cabia ao pesquisador contribuir para a produção de conhecimento e, ao mesmo tempo, para remover do cotidiano escolar "a ação rotineira e as opiniões empíricas", tornando assim os educadores "mais seguros, mais esclarecidos sobre a tarefa que executam" (idem, p. 92). ${ }^{11}$

Nesse artigo, Jayme Abreu fazia referência a idéias contidas em um ensaio de Anísio Teixeira dedicado a elucidar as relações entre ciência e arte na educação, no qual o autor, mencionando John Dewey, dizia:

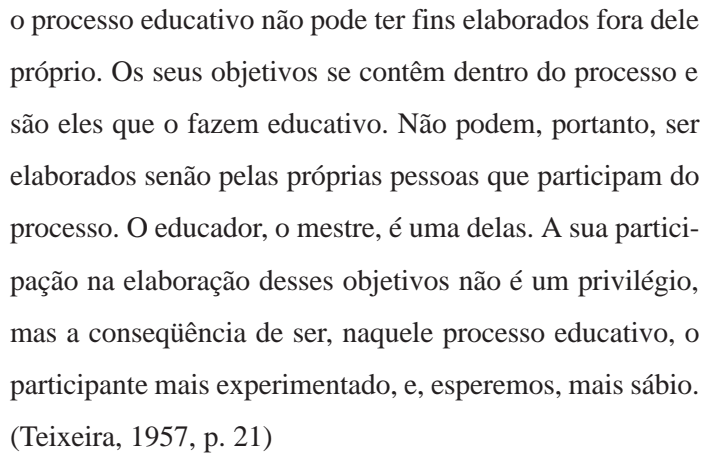

Enfim, o processo pedagógico era descrito como processo ativo, que se altera a cada momento e não pode ser contido em fórmulas abstratas. Só quem participa desse movimento ágil e sujeito a alterações constantes pode compreendê-lo realmente e, assim, conduzi-lo, desde que possua a sabedoria e a experiência necessárias. O educador competente para tanto é o profissional forjado por condições subjetivas oriundas de sua vivência coletiva e implementadas por saberes científicos.

\section{Considerações finais}

Conforme visto nas páginas precedentes, o pensamento de John Dewey foi utilizado pelos educadores brasileiros, no período e nas fontes estudadas, para

${ }^{11}$ Em outro artigo, Abreu (1959) discorre sobre o papel da escola como fator de mudança cultural. discutir a educação no campo dos valores fundamentais do homem e da vida em sociedade. A característica marcante de todos os discursos inspirados na filosofia deweyana é que tais valores não são dados $a$ priori, mas buscados na situação de um mundo em permanente mudança. Sob a influência de Dewey, a perspectiva de fundar a educação sobre princípios normativos implicava que estes jamais fossem estabelecidos de maneira definitiva, fixa e categórica, dado que a realidade é algo em permanente movimento.

Por intermédio de autores como os que foram aqui analisados, representantes da influência de John Dewey no Brasil, o pensamento educacional renovador incorporou a idéia de que a definição das finalidades educacionais devia fazer-se em meio ao questionamento da ordem social como estado definido e fixo da história humana. A promoção do debate incessante e nunca concluído, somente possível em ambiente verdadeiramente democrático, visto como ideal ou como profecia, segundo palavras de Anísio Teixeira, garantia a liberdade imprescindível para a edificação de um mundo melhor no futuro. As práticas pedagógicas e as atividades de pesquisa educacional, nesse contexto, não podiam ser guiadas por outros referenciais que não os da mobilidade permanente do homem e do mundo por ele criado, sem que isto traduzisse submissão do indivíduo à ordem social e econômica.

Mas o ideário educacional renovador desenvolvido no Brasil a partir dos anos de 1920 não foi, todo ele, inspirado em concepções deweyanas. Embora Dewey seja mencionado por muitos educadores, a Escola Nova deweyana é apenas uma das muitas faces do escolanovismo (Cunha, 2000). Houve também um escolanovismo francamente taylorista e funcionalista, com marcada ênfase na eficiência dos procedimentos escolares, na simples adequação do indivíduo à ordem social e ao ritmo da indústria em ascensão. Por essa via, fundada na idéia de progresso inevitável e linear da civilização, a ciência era tida como palavra-de-ordem indiscutível, o que reduzia os fins educacionais à mera assimilação dos meios sugeridos pelas revelações científicas. Noções como rendimento, maximização de resultados, minimização de esforços e racio- 
nalização de procedimentos voltavam o olhar dos educadores para a sociedade capitalista como ponto final e superior do desenvolvimento humano (Carvalho, 1989, p. 61-62). Tratava-se de um escolanovismo que também continha apelos à idéia de mundo em movimento.

O quadro em que se desenvolveu a Escola Nova foi marcado pelas circunstâncias do avanço da sociedade capitalista, o que pode explicar as diversas faces desse movimento pedagógico. Nenhum outro sistema de produção e circulação de mercadorias confere tanta ênfase à necessidade e urgência de as pessoas aceitarem alterações na ordem existente. O progresso tecnológico e as imposições da lucratividade determinam que todos estejam disponíveis para adequar-se às novidades, o que certamente responde pela difusão do tema da transformação constante, levando-o a ocupar posição de centralidade no discurso pedagógico, tanto no Brasil quanto nos Estados Unidos de John Dewey.

Como nem todas as características da sociedade capitalista contribuem para a manutenção e a busca do modo de vida cooperativo em benefício de todos a democracia, conforme a definição deweyana -, a temática da mudança tinha o potencial de desencadear discussões políticas no campo da educação. Para os seguidores de Dewey, aceitar a mudança, a transitoriedade, a alteração das coisas, não significava senão colocar o mundo à disposição do bem-estar coletivo, algo diverso do que se via em outras concepções de Escola Nova. Algo diverso do que se vê, também, na atualidade, quando o discurso mudancista posiciona as pessoas para a busca individual do sucesso, muitas vezes às custas de outrem, e para a aceitação passiva do fracasso, como se este fosse uma decorrência natural e inevitável das mudanças econômicas e sociais.

Não é objetivo do presente estudo discorrer sobre este assunto, é certo, mas a menção a ele é útil para que pensemos - e pesquisemos - um pouco mais sobre o modo como as idéias de John Dewey devem ser entendidas mediante o incessante movimento do mundo atual. Afinal, o pragmatismo deweyano não foi elaborado para descansar nas estantes das bibliotecas, para sustentar uma sociedade desumana ou para dar crédito à passividade, mas sim para implementar a compreensão e a alteração da ordem do mundo em benefício do enriquecimento contínuo da experiência humana - o que os educadores analisados no presente estudo, ao que parece, viram muito bem.

MARCUS VINICIUS DA CUNHA é livre-docente e professor-adjunto do Departamento de Psicologia da Educação e do Programa de Pós-Graduação em Educação Escolar da Faculdade de Ciências e Letras da Unesp/Araraquara (SP). Publicações mais recentes: a coletânea Ideário e imagens da educação escolar (Autores Associados, 2000), o artigo "John Dewey, a outra face da Escola Nova no Brasil" em Ghiraldelli Jr (org.), O que é filosofia da educação? (DP\&A, 2000) e o livro John Dewey: a utopia democrática (DP\&A, 2001). E-mail: mvcunha@yahoo.com

\section{Referências bibliográficas}

ABREU, Jayme, (1958). Filosofias da educação e pesquisa educacional. Educação e Ciências Sociais, v. 3, n 7, p. 71-97.

(1959). A escola como agente de mudança cultural: do ponto de vista de sua filosofia. Educação e Ciências Sociais, v. $6, n^{\circ} 12$, p. $27-56$.

(1960). Atualidade de John Dewey. Revista Brasileira de Estudos Pedagógicos, v. 24, nº 80, p. 8-16.

ATHAYDE, Tristão de, (1932). O problema pedagógico. Educação, v. $7, \mathrm{n}^{\circ} 4-5$, p. $74-81$.

CARVALHO, Marta Maria Chagas de, (1989). A escola e a República. São Paulo: Brasiliense.

(1998). Molde nacional e fôrma cívica: higiene, moral e trabalho no projeto da Associação Brasileira de Educação (1924/1931). Bragança Paulista: EDUSF.

CUNHA, Marcus Vinicius da, (1991). A educação no período Kubitschek: os Centros de Pesquisas do INEP. Revista Brasileira de Estudos Pedagógicos, v. 72, n 171, p. 175-195.

(1999a). A presença de John Dewey na constituição do ideário educacional renovador. Educação em Revista, n 30 , p. 77-91.

(1999b). Três versões do pragmatismo deweyano no Brasil dos anos 50. Educação e Pesquisa, n 2, p. 39-55.

(2000). John Dewey, a outra face da Escola Nova no 
John Dewey e o pensamento educacional brasileiro

Brasil. In: GHIRALDELLI JR., Paulo (org.). O que é filosofia da educação? Rio de Janeiro: DP\&A.

(2001a). Dewey, Escola Nova e Construtivismo: continuidade, descontinuidade e recontextualização. In: ALMEIDA, Jane Soares de. Estudos sobre a profissão docente. São Paulo: Cultura Acadêmica.

, (2001b). John Dewey: a utopia democrática. Rio de Janeiro: DP\&A

DEWEY, John, (1959a). Democracia e educação: introdução à filosofia da educação. $3^{\text {a }}$. ed. São Paulo: Nacional. Tradução de Godofredo Rangel e Anísio Teixeira.

(1959b). Reconstrução em filosofia. 2a ${ }^{\mathrm{a}}$. ed. São Paulo: Nacional. Tradução de António Pinto de Carvalho.

(1970). Liberalismo, liberdade e cultura. São Paulo: Nacional. Tradução de Anísio Teixeira.

KILPATRICK, William H., (1975). Educação para uma civilização em mudança. 13a . ed. São Paulo: Melhoramentos. Tradução de Noemy S. Rudolfer.

LOURENÇO FILHO, Manuel B., (1939). A pedagogia norte-americana. Revista de Educação, v. 27, n 27-28, p. 10-20.

MONARCHA, Carlos, (1997). Lourenço Filho e a "Bibliotheca de Educação". In: (org.). Lourenço Filho: outros aspectos, mesma obra. Campinas: Mercado de Letras.
MOREIRA, João Roberto, (1954). O valor da ciência e os estudos educacionais. Revista Brasileira de Estudos Pedagógicos, v. 21, $\mathrm{n}^{\circ} 53$, p. $21-47$.

, (1956). A educação e o conhecimento do homem pelas ciências sociais. Revista Brasileira de Estudos Pedagógicos, v. $25, \mathrm{n}^{\circ} 62$, p. $41-55$.

(1957). Funções sociais e culturais da escola. Revista Brasileira de Estudos Pedagógicos, v. 27, n 66, p. 53-81.

SUCUPIRA, Newton, (1960). John Dewey: uma filosofia da experiência. Revista Brasileira de Estudos Pedagógicos, v. 24, nº 80, p. 78-95.

TEIXEIRA, Anísio, (1930). A reconstrução do programa escolar. Escola Nova, v. 1, n 2-3, p. 86-95.

, (1955a). Bases da teoria lógica de Dewey. Revista Brasileira de Estudos Pedagógicos, v. 23, n 57, p. 3-27.

(1955b). O espírito científico e o mundo atual. Revista Brasileira de Estudos Pedagógicos, v. 23, n 58, p. 3-25.

(1956). O processo democrático de educação. Revista Brasileira de Estudos Pedagógicos, v. 25, nº 62, p. 3-16.

(1957). Ciência e arte de educar. Educação e Ciências Sociais, v. $2, \mathrm{n}^{\circ} 5$, p. $5-22$.

(1959). Filosofia e educação. Educação e Ciências Sociais, v. $6, \mathrm{n}^{\circ} 12$, p. $9-25$ 
The appropriations of Pierre Bourdieu's work in the brazilian educational field

Based on research carried out in 20 specialised educational periodicals, published between 1971 and 2000, the present text analyses the forms of appropriation from Pierre Bourdieu's work in the field of Brazilian education. The set of 355 articles published in those periodicals that make reference to the sociologist constitutes the basic corpus for the analysis of the peculiarities of the Brazilian interpretations of this author.

Marcus Vinicius da Cunha

John Dewey e o pensamento educacional brasileiro: a centralidade da noção de movimento

$\mathrm{O}$ trabalho analisa artigos publicados em periódicos educacionais brasileiros entre 1930 e 1960, cujos temas são educação, democracia, filosofia, ciência e verdade, entre outros, desenvolvidos segundo concepções de Dewey. Em todos, ocupam posição central as noções de mudança e transformação, em oposição a estabilidade, fixidez e permanência. O objetivo é mostrar a relevância da noção de mundo em movimento, tanto para os brasileiros quanto para Dewey.

John Dewey and the brazilian educational thinking: the main position of the concept of change This paper analyses some articles published by educational journals in Brazil between 1930 and 1960, whose subjects are education, democracy, philosophy, science, truth and others, developed according to Dewey's ideas. In all of them, the main concept is the transformation of things, in opposition to steady. The central intent is to show the change of world like a key concept to the brazilian authors, as such as to Dewey.

\section{Sandra Mara Corazza}

Currículos alternativos/oficiais: o(s) risco(s) do hibridismo

$\mathrm{O}$ artigo enfatiza similaridades discursivas entre os PCNs do Ministério da Educação do Brasil, tidos como currículo oficial, e o Movimento Constituinte Escolar do governo petista do Rio Grande do Sul, proposto como currículo alternativo. Reflete sobre o que vem acontecendo com nossos currículos alternativos críticos, que acabam propondo quase a mesma educação que a do Governo Federal. Argumenta que, em função desse hibridismo, precisamos desfazer o risco de ligação, produzir e praticar currículos que ainda não existem, inventar mais uma vez a diferença.

\section{Alternative-official curricula: the} risk(s) of hybridism

The article stresses the discursive similarities between the National Curricula Parameters (PCN) established by the Brazilian Ministry of Education, considered the official curriculum, and the School Assembly Movement inspired by the Workers' Party state government in Rio Grande do Sul, proposed as an alternative curriculum. It discusses what has been happening with our critical alternative curricula which end up proposing almost the same education as that of the Federal Government. It forwards the argument that, as a consequence of this hybridism, we need to dispel the ambiguity, by producing and putting into practice curricula which do not yet exist and to invent once more the difference.

Reinaldo Matias Fleuri

Entre o oficial e o alternativo em propostas curriculares: para além do hibridismo

$\mathrm{O}$ texto discute a relação entre o oficial e o alternativo no discurso da Constituinte Escolar (1999-2000), pro- movida pelo governo do estado do Rio Grande do Sul (BR). Traz contribuições de pesquisadores em educação popular para interpelar os sujeitos (em particular os movimentos sociais populares e as instituições estatais) e discutir a metodologia utilizada neste processo de reformulação curricular. Enfatiza a importância da perspectiva complexa para se compreender os limites e as possibilidades de um processo oficial que pretende promover, paradoxalmente, a inserção dos movimentos sociais alternativos na formulação e no controle das diretrizes curriculares da escola pública.

Between the official and the alternative in curricular proposals: beyond hybridism

The text discusses the relationship between the official and the alternative discourse used in the School Assembly (1999-2000), sponsored by the state government of Rio Grande do Sul, in the south of Brazil. It presents contributions from researchers in the field of Popular Education with the purpose of inciting the subjects (specifically the popular social movements and state institutions) to reflect upon their practices and to discuss the methodology employed in this process of curriculum reform. It also emphasizes the significance of the complex perspective for understanding the limits and possibilities of an official process aimed at promoting, paradoxically, the participation of the alternative social movements in the formulation and control of curricular guidelines for the state school.

Creso Franco

O SAEB - Sistema de Avaliação da Educação Básica: potencialidades, problemas e desafios

Baseado em contribuição preparada no contexto da Comissão de Especialistas, 